\title{
Analyzing Assessment Practices for Indigenous Students
}

\author{
Jane P. Preston ${ }^{1 *}$ and Tim R. Claypool ${ }^{2}$ \\ ${ }^{1}$ University of Prince Edward Island, Charlottetown, PE, Canada, ${ }^{2}$ University of Saskatchewan, Saskatoon, SK, Canada
}

The purpose of this article is to review common assessment practices for Indigenous students. We start by presenting positionalities-our personal and professional background identities. Then we explain common terms associated with Indigeneity and Indigenous and Western worldviews. We describe the meaning of document analysis, the chosen qualitative research design, and we explicate the delimitations and limitations of the paper. The review of the literature revealed four main themes. First, assessment is subjugated by a Western worldview. Next, many linguistic assessment practices disadvantage Indigenous students, and language-specific and culture-laden standardized tests are often discriminatory. Last, there is a pervasive focus on cognitive assessment. We discuss how to improve assessment for Indigenous students. For example, school divisions and educators need quality professional development and knowledge about hands-on assessment, multiple intelligences, and Western versus Indigenous assessment inconsistencies. Within the past 20 years, assessment tactics for Indigenous students has remained, more or less, the same. We end with a short discussion addressing this point.

Keywords: indigenous people, aboriginal people, first nation education, student assessment and evaluation, document analysis

\section{INTRODUCTION}

Perso and Hayward (2020) described student assessment as "an ongoing process of gathering evidence to determine what students know, understand and can do" (p. 167). A teacher assesses students in many ways including oral responses, tests, student demonstrations, and group projects, for example. The effectiveness of assessment is important, because assessment has power and gatekeeping functions (Nagy, 2000) Assessment determines grades, class choices, pedagogy, curriculum, sometimes the location of one's school, graduation, and college/university eligibility. Moreover, assessment practices and results can create prevailing beliefs about one's ability to learn and succeed, academically, physically, emotionally and socially, in school and life, in general. However, not all forms of assessment are effective. Trumbull and Nelson-Barber (2019) explained that for both Indigenous and non-Indigenous students, many common assessment practices are ineffective and sometimes even detrimental.

Much research shows that when educational curricula and pedagogy are imbued with Indigenous knowledge and ways of knowing, Indigenous student learning improves (e.g., Lipka et al., 2005; Kanu, 2007; Preston \& Claypool, 2013; Preston, 2017; LaPierre, 2019). For example, Lipka et al. (2005) found that Inuit students who experienced math lessons imbued with Indigenous handson activities performed better on standardized tests, compared to Inuit students who did not experience this specialized pedagogy. However, when searching for research focusing solely on assessment practices for Indigenous learners, there is a deep void. In other words, the question that is 
under-researched is: what methods and approaches to assessment are most compatible with and supportive of educational success ${ }^{1}$ for Indigenous students?

The purpose of this paper is to review the literature pertaining to assessment practices of and for Indigenous students. To begin, we present our positionality and explain common terms associated with Indigeneity and Indigenous and Western worldviews. We describe the meaning of document analysis, the chosen qualitative research design, and we identify the delimitations and limitations of the paper. We discuss the findings and explain how to address challenges associated with assessment for Indigenous students. Compared to the past 2 decades, changes in education are starting to surface, and improvements to assessment practices for Indigenous students is ideally positioned.

\section{POSITIONALITY}

Everything in life begins with the self. Every thought, experience, learning, and belief starts through the personalized filter of the individual. This point holds true for research, as well. In turn, we, the authors, start our research by relaying some personal and professional background information (aka positionality).

My name is Jane Preston, and I am a second-generation German Canadian born and raised in Saskatchewan, Canada. Both sets of my farming grandparents immigrated to Canada fleeing religious persecution in Central Europe. My parents first language was German, but this language was almost never spoken in my home. After the World Wars, within North America, people of German ancestry were sometimes perceived negatively. I know little about my German ancestors, their wisdom, or life experiences, but I am intimately close to my heritage via the gift of my ancestral DNA.

I was raised on dairy and grain farm. From a very early age, I was tasked with helping the family milk cows, tend a large garden, and plant and harvest of crops. I left home at 18 years old, studied to become a teacher, and taught in a First Nation community. As a graduate student, I was contracted by the Saskatchewan government and the public school division to complete a five different Indigenous research projects. After obtaining my $\mathrm{PhD}, \mathrm{I}$ moved to Atlantic Canada and met a Mi'kmaq Elder, and a couple of years later, I co-taught an undergraduate Indigenous education course with him. Shortly thereafter, for about a year, I became his student in a Medicine Wheel course he instructed. As a part of his Indigenous teachings, I participated in many sweatlodge, smudging, and pipe ceremonies, and I learned to sing Mi'kmaq songs in Mi'kmac. Through his teachings, I acquired my sacred bundle, which I used during morning rituals to bolster

${ }^{1}$ For us, educational success is a prekindergarten to high school journey where a student recognizes and assumes their academical, physical, emotional, and spiritual abilities. Our views are in line with the First Nations Holistic Lifelong Learning Model depiction of student success, which is a quadrilateral concept promoting the student's academic, physical, emotional, and spiritual wellness (Canadian Council on Learning, 2007). my physical, mental, emotional, and spiritual wellbeing. I am grateful for this Indigenous knowledge and experience, because now I think about, see, and feel the world in a holistic, colorful, interconnected fashion.

My name is Tim Claypool, and I have European, Canadian, and American roots. My father was a first generation Canadian, born to American immigrants who homesteaded in southwest Saskatchewan. My mother was an Irish immigrant who maintained her ties to her County Cork family throughout her 91 years of life. My parental grandparents also stayed connected with their siblings and extended family in Wisconsin, Minnesota, Montana, Washington, and Alaska. Similar to Dr Preston, I also grew up on a farm close to where my father was born and raised. While attending elementary school in the close-knit village of Beechy, Saskatchewan I never saw a First Nations or Métis student or teacher. Even after our family moved to Saskatoon, I never knew an Indigenous student or teacher in my high school, which had an enrollment of about 1,500 students. It was not until I had completed four years of postsecondary education at the University of Saskatchewan (U of S) and accepted my first teaching position in the village of Dorintosh that I was introduced to First Nations and Métis business owners, community members as well as some students in my classes.

However, it was during my 12 years career to tenured Associate Professor at $U$ of S's College of Education that I began my journey of discovery and understanding of some Indigenous worldviews and ways of knowing. By participating in Indigenous lead professional development opportunities and assisting with the planning an international conference for Indigenous scholars and allies, I became aware of significant gaps in my education and training, which only provided cursory acknowledgement of Indigenous peoples and typically steered clear of potentially contentious facts related to residential school atrocities, intergenerational trauma, and anti-Indigenous forms of racism. Thankfully, I came to know several Indigenous Elders and scholars who had the patience to help me understand basic teachings and traditions. Additionally, I have participated in Elder and Knowledge Keeper lead ceremonies that were integrated into my research, teaching, and service work as a faculty member. I also want to acknowledge the Indigenous undergraduate and graduate students with whom I have had the privilege to work over the years. Sometimes, the teacher needs to become the student when there are so many significant gaps in one's formal and informal education. My journey of understanding and supporting Canada's First Peoples continues.

\section{TERMS AND CONCEPTS}

Within this paper, some important terms requiring an explanation include: Indigenous, Aboriginal, First Nation, Metis, and Inuit. Also, throughout the paper, we address issues related to Indigenous and Western worldviews. Due to paper length restriction and the focus of this article (i.e., assessment practices), only an abridged explanation of these worldviews is provided. 


\section{Indigenous Terms}

Within Canada, for several decades, the word Aboriginal, predominantly, was used when describing the original inhabitants of Canada. However, these days, a preferred term is Indigenous. The use of the word, Indigenous, was politically supported in 2015 when the Canadian Ministry of Aboriginal Affairs and Northern Development was officially renamed Indigenous and Northern Affairs Canada (Lum, 2015). Currently, the term, Indigenous, is regularly used within international discourse, discussions, and protocols when referring to the original inhabitants of a country or region (McMillan \& Yellowhorn, 2004). Within Canada, Indigenous peoples include three groups: First Nations, Metis, and Inuit. "The term Indigenous refers to all of these groups, either collectively or separately" (Queen's University, 2019, p. 2). First Nation peoples refers to members of legally recognized bands or reserve-based communities in Canada (Peters \& Mika, 2017). "Métis refers to the distinct society that emerged through the union of Indigenous and non-Indigenous cultures during the period of European expansion in Western Canada" (Lakehead University, 2020, para 3). Inuit refers to the cultural and linguistic (i.e., Inuktitut) identity of Indigenous peoples whose traditional land is located in the Arctic regions of Canada, Alaska, and Greenland (Lakehead University, 2020). With specific global regions, Indigenous peoples are referred to in various ways. For example, Indigenous people of northern Norway, Finland, Sweden, and Russia are called Sami (Stosowana, 2016), and the Indigenous people of New Zealand are called Māori. Within this article, whenever possible and appropriate, we use the term, Indigenous; however, based on the reference source or context, any of these terms may be used.

\section{Worldviews: Indigenous and Western}

A worldview is the way in which a person conceptualizes and makes meaning of the world (see Preston, 2019). It is a framework of one's core beliefs and embodied knowledge (Hedlund-de Witt, 2012; Braaten \& Huta, 2017); it is a standard of ethics by which to live. A worldview is a set of assumptions, both conscious and subconscious, about how society functions. It is an interpretative framework by which good/bad and order/disorder are categorized and judged. From infancy through adulthood, a person's worldview is absorbed and created via language, culture, and social interactions. This worldview is solidified as a child grows and engages in cultural practices, family interactions, educational experiences, rewarding and challenging experiences, social interactions, and expectations of society. One's worldview informs and defines a person, provides a sense of purpose and direction in life, venerated values, dictates decision-making, and informs standards of conduct. Jacobs (2020) proposed that there are only two worldviews-the Indigenous worldviews ${ }^{2}$ and the dominant Western worldview.

\footnotetext{
${ }^{2}$ The plural term, "worldviews", is intentional. It is an attempt to respect and acknowledge the different perspectives among Indigenous people, communities, and Nations.
}

"The Indigenous worldview(s) encourages the expression of authentic reverence for women, gender fluidity, egalitarianism, cooperation, honesty, wellness, peace, harmony, restorative justice, democracy, ecological sustainability, and nonhierarchical organizational structures" (Jacobs, 2020, p. xxxix). Within such an existence, the ultimate purpose of life is to learn to "(live) in harmony with all relations, both human and non-human" (Jacobs, 2020, p. xi). Indigenous worldviews are about interconnected wholeness-every aspect of the world is directly and indirectly connected to every other aspect. Because there is no separation between nature and being human, all forms of creation possess one consciousness (Bastien, 2003). Donald (2016) explained, “The Sun, the land, the wind, the water, the animals, and the trees (just to name a few) are quite literally our relatives. We carry parts of them inside our own bodies" (p. 10). All matter is connected via shared energy, which radiates within and throughout every human being. Indigenous worldviews see knowledge, experience, and life as unified and holistic.

A Western worldview ${ }^{3}$ also has a number of defining characteristics (see Preston, 2019; Jacobs, 2020). Humans are separate from nature. Human are the most important, advanced living creature and situated at the top of the pyramid of living things. A Western worldview sees the inanimate environmental presence of such things as rocks, rivers, mountains, grass, and plants as void of spirit. The modern Western society, which is secular and materialistic, tends to negates spiritual values (Hassed, 2000). Things that are measurable and quantifiable are real. Individuality and competition are important, and often, defining characteristics of life. Authority figures and institutions have power and influence, because domination and control over one another is related to survival. This worldview sanctions external rewards and punishments as motivators. A Western worldview reinforces the idea that the most of the curriculum taught in school is information that can be assessed through pen-and-paper-type assignments and tests. A Western worldview sees knowledge, experience, and life as compartmentalized into sometimes/often unrelated entities (Hart, 2010).

\section{METHODOLOGY, LIMITATIONS, AND DELIMITATIONS}

This qualitative research focusing on assessment practices for Indigenous students is a document analysis. As defined by Bowen (2009), a document analysis is "a systematic procedure for reviewing or evaluating documents-both printed and electronic (computer-based and Internet-transmitted) material" (p. 27). In simple terms, Glass (1976) described this process as an "analysis of analyses" (p. 3). Similar to a literature review, conducting a document analysis involves compiling, examining, and interpreting published data about a specific

${ }^{3}$ For us, the term Western worldview is synonymous with Eurocentric or Eurowestern worldview. 
topic, and it uncovers patterns and thematic consistencies to elicit meaning and gain practical knowledge (Corbin \& Strauss, 2008; Bowen, 2009). In contrast, a literature review not only analyzes the research associated with a specific topic, it highlights the gaps in the research area and compares past studies to the researcher's prescribed study (Merriam \& Tisdell, 2016). These two points are not features of document analysis.

The first step for this document analysis was data collection, which involved a literature search using the University of Prince Edward Island's (Canada) library database system, Google Scholar, and ResearchGate. Through these systems, we accessed international databases such as EBSCO, ERIC, JSTOR, Education Research Complete, and others. We found books, chapters in books, journal articles, dissertations, conference papers, magazines, policy documents, and other Internet-accessible documents related to Indigenous student assessment. The following search terms and their combination were used: "Indigenous student" "Aboriginal student" "First Nation student" "Metis student" "Inuit student" "Native student," "student assessment," "student learning," "culturally responsive assessment," "student outcomes," and "student success." With regard to Indigenous student assessment, we welcomed information from any age, grade, or educational program from early childhood to postsecondary education. Ensuing titles, abstracts, and/or content were scanned and judged to determine if the documents were appropriate for our research topic. From our efforts, we collected and digitally saved, 63 of what appeared to be relevant articles, chapters in books, and other online documents. After this topical literature was obtained, we completed a more thorough scan of each document by rereading abstracts and reading headings, reading full paragraphs, topic sentences, and the findings section, for example. After this indepth review, we found only 40 of the 63 documents addressed on our research purpose-documenting common assessment practices for Indigenous students.

One of the authors printed the 40 documents. With the hardcopies of the documents in hand, the author read each source in detail underlining key passages, and, in the margins, jotted down paraphrased notes, findings, and/or phrases. After a few documents were analyzed, similar paraphrased words started to repeat (e.g., culture, language, cognition, standardized tests, etc.) These repeated phrases were the genesis of the creation of final themes. Our analysis of documents and semi-established themes was a process similar to thematically analyzing or coding interview transcripts. As Patton (2015) explained, coding involves finding patterns, establishing categories from the patterns, and creating overarching themes based on the categories. After having read all the papers, the author spent time reflecting on all the semiestablished themes to create the overarching themes of this paper.

A number of delimitations [techniques for deliberately narrowing the research focus (O'Leary, 2017)], were applied to the research. To be included in our analysis, papers had to be published during the 20-year period of 2000-2020; they had to be published in English and provide insights about Indigenous student assessment. With regard to limitations [design characteristics that limit the generalizability of the findings (O'Leary, 2017)], we attempted to access documents worldwide; however, due to confinements of our library databases and our firsthand knowledge of Indigenous content, the retrievable literature reflected studies from Canada, Australia, New Zealand, the United States, and Norway. Also, because this paper was written during Covid-19 pandemic, access to physical books was limited to our personal libraries.

\section{THEMATIC ANALYSIS OF THE LITERATURE}

From the analysis of documents, four overarching themes surfaced. First, Indigenous student assessment remains subjugated primarily by a Western worldview. Second, much of the mainstream culture-infused, linguistic-laden practices of assessment disadvantage Indigenous students. Third standardized tests can be discriminatory when administered and interpreted inappropriately. Last, assessment primarily focuses on cognitive abilities. An explanation of these themes and the associated literature are provided below.

\section{Assessment Subjugated by Western Worldview}

Western knowledge and values directly and implicitly dominate schools, including, for example, the curriculum, organization of grades, organization of classrooms, expected styles of speaking, norms for interacting, instructional pedagogy, and assessment practices (Trumbull \& Nelson-Barber, 2019). When reviewing the types of assessment techniques used with Indigenous students, Westernized forms of assessment are pervasive (Nelson-Barber \& Trumbull, 2007; Fleet \& Kitson, 2009). Popular types of Westernized assessment include written quizzes, tests, and exams, which primarily promote academic development via rational, linear, and accountable activities. Moreover, such assessment is largely focused on meeting curricular outcomes, and it tends to neglect the physical, emotional, and spiritual domains of students (Claypool \& Preston, 2011).

Much of the literature denotes how Western assessment practices are culturally insensitive and potentially discriminatory to Indigenous students. Mainstream assessment practices do not sufficiently account for the social, economic, and political factors that contribute to the learning challenges experienced by many Indigenous students (Canadian Council on Learning, 2007). Stoffer (2017) stated, "Assessing a child in a way that does not seem meaningful or relevant to their life and culture is inauthentic and therefore meaningless, because it does not respect the learning of the whole child" (p. 66). From a holistic Indigenous standpoint, education is about gaining life skills; it is about communicative interactions, social relationships, self-discovery, and self-growth. In turn, assessment and selfassessment need to focus on the diversity of learning; the whole learning experience.

Grounded in Indigenous epistemology, learning is a holistic process, and assessment should include a personalized tactics. For example, within the subject of science, Friesen and Exeife (2009) call on assessment practices that address the sociocultural influence that shape student thinking. Moreover, they explain 
that teachers need to understand Indigenous culture in order to create culturally valid assessments. Unfortunately, test items often contain information not privy to an Indigenous student who might embody a worldview other than Western. The content and mode of assessment tasks may be outside an Indigenous student's cultural and linguistic knowledges and ways of knowing (Klenowski, 2009) To address this point, researchers state that cultural congruency or culturally validity of assessment practices, test items, and test formats is a vital component of assessment of and for Indigenous students (Demmert, 2005; Nelson-Barber \& Trumbull, 2007). Worldwide, mainstream curricula are dominated by favored facts, housed within objectives, goals, and outcomes that every student must learn; this conceptualization is rooted in the Western philosophy of education (Betts \& Bailey, 2005).

\section{Mainstream Language Disadvantages}

Language is intricately woven into every assessment practice. In fact, Trumbull and Solano-Flores (2011) viewed language as the greatest component of cultural validity in assessment. For many Indigenous students, their assessment scores are not valid, because the words and composure of test questions and items are biased toward the dominant language, for example, either English or French depending on the region or Canadian province being considered. The National Academy of Education (2021) (an American research association) agreed, "Assessments themselves are potentially subject to inequities in design, content and language choices" (p. 11) In sum, in assessment, language matters and has the power to disadvantage learners.

Özerk, and Whitehead (2012) stated that language policies associated with the national assessments in New Zealand and Norway disregard the Indigenous language rights of Māori and Sámi students. When Indigenous students whose first language or primary school community language is not English, assessment techniques are not straight-forward. Moreover, Trumbull and Nelson-Barber (2019) explained that students exposed to more than one language have their knowledge organized differently. They may know some concepts and words in one language and not the other(s) In such cases, assessment should be done in the language and/or mixture of languages of their choice. According to the Norwegian Directorate for Education and Training (2010, as cited by Özerk \& Whitehead, 2012) standardized tests in mathematics do not simply test the subjects of mathematics; they also evaluate how well a student can read the language of the test. With regard to a postsecondary Vocational Educational and Training online course delivered to Aboriginal and Torres Strait Island students in Australia, Wilks et al. (2020) explained that instructors need to be creative in the way learning is assessed so Indigenous students are not restricted to written assignments of standard English. Also, adapting and/or translating tests to the mother tongue of minority (Indigenous) student is an aspect of improving assessment (Solano-Flores \& Nelson-Barber, 2001; Solano-Flores et al., 2002; Kieffer et al., 2009; Robinson, 2010). However, due to transcription inefficacy of language, it is important to note that not all tests can be simply transcribed.

The above information focuses on Indigenous students who were raised either surrounded or partially surrounded with their cultural language. What about best assessments for Indigenous students for whom English is the primary or only language spoken at home and/or have yet to (re)connect to their Indigenous roots? Although there is no one answer for this question, Wiltse (2011) explained, "Many (Indigenous) students speak a comprehensive dialect of English that is the result of the influence (italics inserted) of the Indigenous language or mother tongue on the English language" (p. 53). In other words, Indigenous students who speak only English and are not (re)connected to their Indigenous histories are still influenced by home environments and cultural DNA. In turn, the minimization of complex language on tests is an important component of culturally friendly assessment techniques (Nelson-Barber \& Trumbull, 2007).

One example of how to improve assessment by focusing on Indigenous language is seen via the Office of Hawaiian Education (Sang \& Worchel, 2017). To start, this governing body does not mandate educational outcomes or assessments within private Indigenous schools. Instead, the Office of Hawaiian Education trusts educators to integrate community members and their values into their school's assessment framework. In turn, educators alongside Indigenous community members identify outcomes that the school community views as valuable. Collectively, teachers and community members map out the learning experiences and effective forms of assessments for each outcome (Johnson, 2013). Another example of Indigenous language and assessment is seen through the Curriculum Research and Development Group at University of Hawaii at Mānoa (2020) In this Department, educators are transcribing (where appropriate) and rewriting Grade 3 and 4 standardized assessment tests to include Hawaiian Indigenous language and culture.

\section{Standardized Tests Can Discriminate}

The disconnect between Indigenous ways of knowing and Western assessment is blatant in large-scale or standardized testing. Within public education, students are often evaluated on their performance on standardized, decontextualized testing, a practice that mandates Indigenous students to navigate their learning via the school's Western worldview (Johnson, 2013). Within a Canadian context, for example, common standardized tests include the Programme for International Student Assessment (PISA), the Pan-Canada Assessment Program (PCAP), and various provincial assessment tests. Having stated such, it is important to note that not all Canadian school regions rely on large-scale forms of standardized testing, and individual schools can opt out of PISA test (Anders et al., 2021).

The appropriate use of standardized tests is often a contentious issue. Before relaying the about standardized test, a description of their psychometrics is helpful. First, all forms of assessment, standardized or not, have sources of error. Consequently, test developers include errors in measurement into their formulas for calculating a range of scores (aka confidence intervals) representing where the "true score" lies. The individual's actual test score is believed to be an estimate that is time and place sensitive. However, classical test theory's "observed score $=$ true score + error" formula is scrutinized 
when standardized tests are misused. Perhaps this point is the source of the derision often associated with standardized tests. Having stated such, standardized tests are meant to represent one type of assessment artifact. The onus is on the test user to select a standardized test that meets the following criteria according to the International Test Commission (2019): "Select a test based upon its suitability for the test purpose while taking into account the test and the background characteristics of the targeted population, including all linguistic groups" (p. 374). If a test developer does not include a proportional number of individuals from a selected cultural and linguistic group in their standardization process for their test, then it should not be used with those groups. Information obtained using (or misusing) that standardized test will likely yield information that is unreliable and invalid about those individuals not represented in the test's norming samples during the development process.

Johnston and Claypool (2010) explained that standardized tests can be problematic when attempting to effectively and fairly measure learning and academic success of Indigenous students. Notably, the majority of norm-referenced standardized tests predominately rely on Western knowledge paying little attention to cultural and linguistic barriers that have the potential to disadvantage Indigenous students performance while ensuring more positive outcomes for non-Indigenous test takers. Many authors and organizations stipulate Indigenous students experience a disadvantage during standardized testing, because the biased format and the questions honor Westernized knowledge (Philpott, 2006; Canadian Council on Learning, 2007; Kanu, 2007; Gould, 2008; Bouvier, 2010; Klenowski et al., 2010; Özerk \& Whitehead, 2012; Lee, 2015; Solano-Flores et al., 2015; Stoffer, 2017; Trumbull \& Nelson-Barbar, 2019). Stoffer (2017) concluded that there does not exist a standardized assessment tool that can properly assess Inuit student learning. NelsonBarber and Trumbull (2007) went on to explain that the sources of bias in standardized testing for Indigenous students include test content, language, format, administration, scoring, score interpretation, and usage. In Montana, Dupuis and Abrams (2017) found that American Indigenous students performed better on items based on Indigenous knowledge, compared to mainstream-based questions. Within the area of science, Aikenhead and Mitchell (2011) argued that standardized tests are grounded in Western modern science and disregard Indigenous knowledge and ways of knowing. The need to incorporate Indigenous paradigms into assessment is welldocumented by other researchers (Solano-Flores \& NelsonBarber, 2001; Solano-Flores et al., 2002; Solano-Flores \& Trumbull, 2003), yet the practice of teaching continues to be organized around the dominant model of standardized curriculum and assessment.

\section{An Ineffective Emphasis: The Cognitive Domain}

Effective assessment for Indigenous students utilizes practices that equally focus on physical, emotional, intellectual, and spiritual growth and development (Marule, 2012; Claypool \& Preston, 2014). However, popular assessment practices, especially in middle school and high school, often include multiple choice, fill-in-the-blanks, written short answer, written long answer, powerPoint presentations, essays, group work, demonstrations, and oral presentations, all of which emphasize Westernize intellectual knowledge (Claypool \& Preston, 2011). Such forms of assessment view knowledge as something that can be "given, taken, accumulated, banked, and assessed by paper and pen [or computer] examinations" (Aikenhead \& Mitchell, 2011, p. 68) Cognitive assessment is saturated with Western epistemology, where instructors assess set curriculum to age-appropriate student groupings at set times of the day. As well, teachers assess at specific times, which coincide with the production of individualized report cards, completed and sent home at set times (usually three or four times) during a school year. Assessment for Indigenous students is predominantly an intellectual, quantitative, process-oriented, teacher- and state-dominated powered system.

From a scientific-Western view, spirituality cannot be proven; thus, it is illogical, unsophisticated, and has little to no place in educational assessment. However, logic-infused Western assessment tactics are disconnected with much of the physical, emotional, and spiritual realms of life (Adams et al., 2008). Rameka, (2012) research revealed that early education assessment for Māori students needs to be spiritually located. A spiritual plane combines feelings, sensing, and intuition. Since assessment is evaluating what students do, say, and produce (Smith et al., 2004), to effectively evaluate a Māori student, teachers needed to use their spiritual plane to help them evaluate what the student says, does, and produces. Many teachers may be reticent or directly discouraged from using their intuition or spiritual essence as an assessment practice. Rameka (2012) explained that because spirituality is such a significant feature of Maori ways of knowing and being, Maori recognize spiritual assessment, name it as such, and accept it as a valuable assessment practice.

There is a mistaken belief that assessment is objective; in contrast, all assessment is value-laden, culturally contrived, and biased. Every person subjectively experiences the world through their own values, knowledge, and perceptions. Student assessment is no different. Not only should teachers use their emotions and spirit (i.e., intuition) to assess, Indigenous students should be encouraged to use these same domains to self-reflect on their learning. As a part of self-assessment, student need to be taught and encouraged to use and rely on messages emanating from body, heart, and soul (Claypool \& Preston, 2011). Within a Hawaiian Indigenous context, emotion and spirit were incorporated into effective assessment when teachers asked Indigenous students to complete daily self-assessment rubrics and end-of-the week goals (Johnson, 2013). A number of additional studies highlighted ways in which not only cognitive, but physical, emotional, and spiritual aspects of assessment happen. In a postsecondary course with Indigenous students in Vancouver (Canada), Verwoord et al. (2011), created a Medicine Wheel assessment model, which consisted of four assignment each worth $25 \%$. Each assignment was a self-reflection 
about the academic, physical, emotional, and spiritual aspects of the course. Also, in Alaska, teachers collaborated to create assessment reflective of Inuit student learning, ideologies, and values. For that study, Coles-Ritchie and Charles (2011) found that performance tasks, portfolios, peer assessment, and student self-assessments (all of which aligned with real world tasks) were types of culturally congruent assessment that included all four realms (i.e., academic, physical, emotional, and spiritual) of assessment. Trumbull and Nelson-Barber (2019) identified effective assessment practices for Indigenous students as peer-observation, self-evaluation, and self-reflection, which incorporate emotional and spiritual domains into the assessment practice.

\section{DISCUSSION: EFFECTIVE ASSESSMENT FOR INDIGENOUS STUDENTS}

From the information above, there are many explanations, but limited examples of how to improve assessment for Indigenous students. Herein we provide a discussion to further elaborate on what assessment for Indigenous students is and could be. We use both the literature and our imagination to relay and envision possible sound forms of assessment for Indigenous students.

\section{Dynamic Forms of Assessment}

Riley and Johansen (2019) noted effective assessment practices for Indigenous students are group-oriented and simulate real-life experiences. Such assessment could be a holistic or project-based assignment, as experienced through outdoor education or culture camps (Preston, 2017). Such projects manipulate assessment to be something that is relevant and functional (Johnson, 2013). Also, educators need to incorporate story-focused narratives (Iseke, 2013), personal journals, and portfolios (Kanu, 2007) into their assessment practices. For example, algebra could be taught through storytelling and the utilization of personal symbols relevant to the student (Klenowski, 2009). Tests could be an oral discussion between students and/or student-teacher. What if summative assessment only took place when the student was ready? Also, the concept of letter/number grading and report cards need reconsideration. For example, an alternative to letter/ number grading is a three-level check mark grading system. A check means "acceptable;" a check with a plus sign means "advanced;" a check with a minus sign means "still learning." Ongoing communication between students, teachers, and community members would result in a more holistic and inclusive forms of assessment. Teachers need to collaborate with parents and community members to develop appropriate assessment that stems from culturally sensitive instructional practices. Here, however, it is important to state that there is no "one" Indigenous culture; thus, culturally sensitive practices need to be defined according to the Indigenous context. In order to promote culturally sensitive pedagogy, teacher-community interaction is essential and relationships need to be established and nurtured. As a way for teachers and community members to socially bond before co-creating sound assessment, what about regular school-community potlucks or establishing a community coffee room right in the school? With regard to additional ways to improve assessment, what about open-classroom parent drop-ins where parents can assess, for themselves, how their child is doing?

Taking a sociocultural perspective to assessment might mean students interacting with parents, community members, and Elders to perform various tasks, and the adults assess the students task at hand. Such sociocultural assessment assumes that learning and assessment are socially negotiated and woven into a supportive student-focused community, which values holistic learning, teaching, and assessment. A community form of assessment is not done to students; rather, it's done for and with students. Children develop their thinking, communication, learning, and motivational propensities from the culture into which they are socialized (Vygotsky, 1978). In other words, Indigenous students create meaning from experience in culturally determined ways (Nelson-Barber \& Trumbull, 2007). Their cultural socialization influence how Indigenous students learn, respond to instruction, communicate, and comprehend and respond to assessment tactics (Kanu, 2007). In turn, when creating assessment, teachers need to use the community's "funds of knowledge" (Vélez-Ibáñez , p. 47), which included values, symbols, context, and common practices of the local community.

Moreover, assessment practices for Indigenous students need to be refined so that they reflect multiple forms of intelligences and ways of knowing such as verbal-linguistic, logicalmathematical, visual-spatial, body-kinesthetic, musical, interpersonal-social, intrapersonal, naturalist, and existentialspiritual (Gardner, 1983; Johnson, 2013; Hajhashemi et al., 2018). These abilities and ways of knowing go beyond what the Western world has conceptualized as valid intelligence. For example, a final assessment could be a dance performance that encapsulates physical, emotional, spiritual, as well as intellectual knowledge and wellbeing. Johnston and Claypool (2010) suggested that assessment for Indigenous students include student interviews, behavioral observations, peer-generated assessment, talking/discussion circles to share views and ideas, experiential assessment, and parents, Elders, and community members also serving as evaluators.

\section{Worldviews and Professional Development}

An important step toward improving assessment practices for Indigenous students is to recognize one's worldview and pedagogical assumptions (Carjuzaa \& Ruff, 2010). When a teacher and student embody different worldviews, assessment expectations are mismatched. Many teachers adhere to Western worldview assessment techniques that are rigid, formal, direct, and task-focused. As mentioned, such assessment standards are based on knowledge that is positivistic, mechanistic, compartmentalized, and, inherently, correct/incorrect. Teachers, principals, and policymakers need to recognize and understand the sociocultural circumstances and worldview of Indigenous students (Klenowski, et al., 2010). By adopting a sociocultural understanding to how Indigenous students learn and know, educators become better evaluators. Educators must learn to be culturally safe in their assessment practices (Stoffer, 2017). Through quality professional development, educational leaders and school divisions need to support teachers in their 
efforts to develop and implement Indigenous assessment practices and confront assimilationist assessment tactics in their school environment (Coles-Ritchie \& Charles, 2011). This professional development cannot be generic; it must welcome participation from Elders, community members, and Indigenous educators who understand the local Indigenous culture. To ensure meaningful professional development in this area, research shows that educational school divisions need to invest in long-term support and resources; sustained effort toward professional development is more effective than one-day workshops (Wylie et al., 2009).

A way to address and realign mismatched worldviews with regard to assessment is reflected by the Ministry of Education, Government of Saskatchewan's (2018) Inspiring Success: First Nations and Métis PreK-12 Policy Framework. One of the five policy goals of that framework is to ensure, "culturally appropriate and authentic assessment measures that foster improved educational opportunities and outcomes (for First Nation and Metis students)" p. 14. For this framework, representatives of First Nations peoples, Metis peoples, the provincial government, the postsecondary education sectors, and the public school systems united and agreed that culturally appropriate assessment was a pillar for educational improvement for Indigenous students. This policy agreement is a first vital step of successful multi-worldview cooperation.

\section{Assessment Inconsistencies via Culture}

A final aspect of describing assessment for Indigenous students is to remind educators of inconsistences between Western and Indigenous cultures. Upon first read, these inconsistencies may appear minor; in contrast, if teachers are able to recognize these inconsistences and their meanings, they will be well on their way to improving their assessment for Indigenous students.

To start, teachers need to be aware the Indigenous knowledge is commonly passed through stories and not through direct questions and reply answers. "Direct questions are often considered rude, because you are putting people on the spot (Piquemal \& Nickels, 2005, p. 127). A heavy reliance on verbal demonstration of learning is not culturally congruent for many Indigenous students (Carjuzaa \& Ruff, 2010; Riley \& Johansen, 2019). In Piquemal and Nickels (2005) study of kindergarten Indigenous students in Manitoba, Canada, they did not raise their hand to answer a question as often as the non-Indigenous peers. Raising one's hand can mean a student has the answer, is competing with classmates, and is showing off, all of which is not culturally congruent with cooperation and noncompetitiveness. A possible substitute to direct questioning of individual students is for the teacher to ask for choral responses (Trumbull \& Nelson-Barber, 2019) and/or ask students to write responses on mini whiteboards, which they then hold up (Trumbull et al., 2015).

Second, Indigenous norms of communication include listening more and speaking less. For many Indigenous cultures silent pauses are used to listen, show respect, or consensus (Queensland Government, 2015). This positive use of silence is often misread in Western worldview as a student being passive or indifferent. Third, in many Indigenous cultures, eye contact is considered rude (Queensland Government, 2015). Thus, assessment should not be based on eye contact. Fourth, for many Indigenous learners, traditional values including the concepts of sharing, non-competitiveness, reluctance to speak out, and noninterface. Educators need to reflect on the importance and meaning of these values and ensure they are honored within assessment practices.

Fifth, utilizing an Indigenous worldview, it is considered disrespectful to attempt a task before one can perform it relatively well. From a Hawaiian Indigenous perspective, attaining mastery in one's professional craft is a primary goal, because the survival of the group demands it (Johnson, 2013). Indigenous peoples would not be asked to perform their craft publicly until they were adept at it. In turn, it is important to provide opportunities for Indigenous students to practice privately before performing publicly. Furthermore, instead of the teacher, it is the student who is left to determine when they are ready to perform (Nelson-Barber \& Trumbull, 2007).

The concept of timed assessment also needs reconsideration. For example, time restrictions on tests penalize some/many Indigenous students whose culture values reflection, rather than quick responses as a measure of intelligence. Also, Riley and Johansen (2019) reminded educators that, when assessing discussions, ample time should be given to Indigenous students who want to fully contemplate an answer before speaking.

A final issue pertaining to culturally safe assessment targets publishing companies. "Companies who advertise their assessment tools as "culturally unbiased" cannot make such statements" (Stoffer, 2017, p. 68). Educational publishers need to consult with Indigenous communities to ensure they create culturally valid assessments.

\section{CONCLUSION}

Through our review of the past 2 decades of literature pertaining to assessment practices for Indigenous students, we see little change. Why? To address this question, it is important to recognize that, worldwide, public education has not substantially changed in the past 100-200 years (Foundation for Economic Education, 2019). Throughout this time, education has been organized and delivered through an industrial-like system of production and output. Students are divided in same-age groups, face the same curriculum, learn in same timeframe, are assessed the same way, and graduate at the same time. Perhaps this lockstep approach remains unchanged due, in part, to the significant investment of resources from various levels of government where accountability often translates into easy comparables, summarized in charts, tables, and reports. Unfortunately, individual differences, cultureinformed knowledge systems, and personalized measures of success are sacrificed in standardized, system-wide approaches to assessment.

However, at the time of this paper, the world is experiencing myriad, dynamic changes never seen before. By 2030, Artificial Intelligence robots are expected to replace millions of current jobs. 3D printers will compound many new inventions. In the 
near future, people may enjoy a bed-and-breakfast experience on the moon and witness the establishment of colonies on Mars. Nanotechnology could become an integral part of the human body. In addition to these major social, physical, and economical changes, Covid-19 has forced public education, in part, to break down and re-envision what education is and could be. For example, during school closures, teachers almost instantly assumed new online pedagogies and modes of delivery, regardless of whether they had training (Li \& Lalani, 2020). Changes surfaced in the area of assessment, too. During Covid-times, teachers used more formative assessment assignments and fewer to no mid- and end-of-term examinations. Also, in some school divisions, number percentages and letter grading were change to a "pass/fail" evaluation (Contact North Nord, 2020). In many

\section{REFERENCES}

Adams, K., Hyde, B., and Woolley, R. (2008). The Spiritual Dimension of Childhood. London, England: Jessica Kingsley.

Aikenhead, G. S., and Mitchell, H. (2011). Bridging Cultures: Indigenous and Scientific Ways of Knowing Nature. Toronto, ON: Pearson Canada.

Anders, A., Has, S., Jerrim, J., Shure, N., and Zieger, L. (2021). Is Canada Really an Education Superpower? the Impact of Non-participation on Results from PISA 2015. Educ. Assess. Eval. Account. 33 (1), 229-249. doi:10.1007/s11092-02009329-5

Bastien, B. (2003). The Cultural Practice of Participatory Transpersonal Visions: An Indigenous Perspective. ReVision 26 (2), 41-48.

Betts, P., and Bailey, B. (2005). Sharing Complex Visions for Inclusive Schools. Can. J. Native Stud. 25 (2), 417-432.

Bouvier, R. (2010). Aboriginal Education and Assessing Students' Ways of Knowing: Standardized Test vs. Multiple Ways of Knowing. Our Schools, Our Selves 20 (1), 103-117. doi:10.14375/np.9782251900032

Bowen, G. A. (2009). Document Analysis as a Qualitative Research Method. Qual. Res. J. 9 (2), 27-40. doi:10.3316/QRJ0902027

Braaten, A., and Huta, V. (2017). A Preliminary Exploration of How Worldviews Relate to Eudaimonic and Dedonic Orientations. Int. J. Existential Psychol. Psychotherapy 7 (Spec Iss.), 1-11. Available at: http://journal. existentialpsychology.org/index.php/ExPsy/article/view/224/264.

Canadian Council on Learning (2007). Redefining How success Is Measured in First Nations, Inuit And Métis Learning. Ottawa, ON: Author.

Carjuzaa, J., and Ruff, W. G. (2010). When Western Epistemology and an Indigenous Worldview Meet: Culturally Responsive Assessment in Practice. J. Scholarship Teach. Learn. 10 (1), 68-79.

Claypool, T., and Preston, J. P. (2014). Depictions of Educational success: Voices from Grade 12 Aboriginal Students. The First Nations Perspective. The J. Manitoba First Nations Educ. Resource Centre 6 (1), 67-82. Available at: http://www.mfnerc.org/wp-content/uploads/2014/10/Depictions-Success.pdf.

Claypool, T. R., and Preston, J. P. (2011). Redefining Learning and Assessment Practices Impacting Aboriginal Students: Considering Aboriginal Priorities via Aboriginal and Western Worldviews. education 17 (3), 84-95. https:// ineducation.ca/ineducation/article/view/74/561 doi:10.1037/e683152011-019

Coles-Ritchie, M., and Charles, W. (2011). Indigenizing Assessment Using Community Funds of Knowledge: a Critical Action Research Study. J. Am. Indian Educ. 50 (3), 26-41. Available at: https://www.jstor.org/stable/43608611.

Contact North Nord (2020). How Assessment Is Changing in the Digital Age-Five Guiding Principles. Available at: https://teachonline.ca/toolstrends/how-assessment-changing-digital-age-five-guiding-principles (Accessed February 3, 2021) (Government of Ontario).

Corbin, J., and Strauss, A. (2008). Basics of Qualitative Research: Techniques and Procedures for Developing Grounded Theory. 3rd ed. Thousand Oaks, CA: Sage. doi:10.4135/9781452230153 postsecondary settings, remote online final tests were instigated (Reid \& Sam, 2021). Currently, education is experiencing a type of metamorphosis, transforming into something yet to be seen. Due to changes in technology and the consequences of Covid-19, now, more than ever, educators, school divisions, and mainstream society are open to thinking about educating and assessing students in new ways. Amid this transformation, we remain hopeful that assessment for Indigenous students will receive a much-needed upgrade.

\section{AUTHOR CONTRIBUTIONS}

All authors listed have made a substantial, direct, and intellectual contribution to the work and approved it for publication.

Curriculum Research and Development Group, University of Hawaii i i at Mānoa (2020). Hawaiian Immersion Assessment. Available at: https://manoa.hawaii. edu/crdg/evaluation/hawaiian-immersion-assessment/ (Accessed February 6, 2021).

Demmert, W. (2005). The Influence of Culture on Learning and Assessment Among Native American Students. Learn. Disabilities Res. Pract. 20 (1), 16-23. Available at: http://blogs.ubc.ca/dryan/files/2008/10/fulltext.pdf.

Donald, D. (2016). From what Does Ethical Relationality Flow? an "Indian" Act in Three Artifacts. Counterpoints 478, 10-16. Available at: http://www.jstor.org/ stable/45157205.

Dupuis, J., and Abrams, E. (2017). Student Science Achievement and the Integration of Indigenous Knowledge on Standardized Tests. Cult. Stud. Sci. Educ. 12 (3), 581-604. doi:10.31274/itaa_proceedings-180814-258

Fleet, A., and Kitson, R. (2009). Rethinking Assessment in an Indigenous Specific Program. Alberta J. Educ. Res. 55 (3), 397-413.

Foundation for Economic Education (2019). Schools Are Outdated. It's Time for Reform. Available at: https://fee.org/articles/schools-are-outdated-its-time-forreform/ (Accessed February 6, 2021).

Friesen, J. B., and Exeife, A. N. (2009). Making Science Assessment Culturally Valid for Aboriginal Students. Can. J. Native Educ. 32 (2), 24-37. doi:10.1093/acprof: oso/9780195371833.001.0001

Gardner, H. (1983). Frames of Mind: The Theory of Multiple Intelligences. New York, NY: Basic Books.

Glass, G. V. (1976). Primary, Secondary, and Meta-Analysis of Research. Educ. Res. 5 (10), 3-8. doi:10.3102/0013189x005010003

Gould, J. (2008). "Language Difference or Language Disorder: Discourse Sampling in Speech Pathology Assessments for Indigenous Child," in Children's Language and Multilingualism: Indigenous Language Use at home and School. Editors J. Simpson and G. Wigglesworth (London, England: Continuum), 194-215.

Hajhashemi, K., Caltabiano, N., and Anderson, N. (2018). Multiple Intelligences, Motivations and Learning Experience Regarding Video-Assisted Subjects in a Rural university. Int. J. Instruction, 11(1), 167-182. Available at: https://files. eric.ed.gov/fulltext/EJ1165195.pdf. doi:10.12973/iji.2018.11112a

Hart, M. (2010). Indigenous Worldviews, Knowledge, and Research: The Development of an Indigenous Research Paradigm. J. Indigenous Voices Soc. Work 1 (1), 1-16. Available at: https://files.eric.ed.gov/fulltext/EJ1165195.pdf doi:10.1093/oxfordhb/9780195369441.003.0018

Hassed, C. S. (2000). Depression: Dispirited or Spiritually Deprived?. Med. J. Aust. 173 (10), 545-547. doi:10.5694/j.1326-5377.2000.tb139326.x

Hedlund-de Witt, A. (2012). Exploring Worldviews and Their Relationships to Sustainable Lifestyles: Towards a New Conceptual and Methodological Approach. Ecol. Econ. 84 (1), 74-83. doi:10.1016/j.ecolecon.2012.09.009

International Test Commission (2019). ITC Guidelines for the Large-Scale Assessment of Linguistically and Culturally Diverse Populations. Int. J. Test. 19 (4), 301-336. doi:10.1080/15305058.2019.163102g

Iseke, J. (2013). Indigenous Storytelling as Research. Int. Rev. Qual. Res. 6 (4), 559-577. doi:10.1525/2Firqr.2013.6.4.559 
Jacobs, D. T. (2020). The Red Road (Čhajkú Lúta): Linking Diversity and Inclusion Initiatives to Indigenous Worldview. Charlotte, NC: Information Age.

Johnson, Z. (2013). "E Ho 'omau!" A Study of Hawai'i Teachers Navigating Change through Generative Praxis. (Doctoral Dissertation). Stanford, CA: Stanford UniversityAvailable at: https://stacks.stanford.edu/file/druid:sb466ck2013/ ZJohnsonDissertationV30-augmented.pdf.

Johnston, A., and Claypool, T. (2010). Incorporating a Multi-Method Assessment Model in Schools that Serve First Nations, Inuit, and Métis Learners. Native Stud. Rev. 19 (2), 121-138. doi:10.2514/6.2010-2201

Kanu, Y. (2007). Increasing School success Among Aboriginal Students: Culturally Responsive Curriculum or Macrostructural Variables Affecting Schooling? Diaspora. Indigenous, Minor. Educ. 1 (1), 21-41. doi:10.1080/ 15595690709336599

Kieffer, M. J., Lesaux, N. K., Rivera, M., and Francis, D. J. (2009). Accommodations for English Language Learners Taking Large-Scale Assessments: A Metaanalysis on Effectiveness and Validity. Rev. Educ. Res. 79 (3), 1168-1201. doi:10.3102/ 2F0034654309332490

Klenowski, V. (2009). Australian Indigenous Students: Addressing Equity Issues in Assessment. Teach. Educ. 20 (1), 77-93. doi:10.1080/10476210802681741

Klenowski, V., Tobias, S., Funnell, B., Vance, F., and Kaesehagan, C. (2010). Culture-fair Assessment: Challenging Indigenous Students through Effortful Mathematical Teaching. Paper presented at the Australian Association of Research in Education, Melbourne, Australia, Available at: https://www.aare. edu.au/publications/aare-conference-papers/show/6055/culture-fair-assessmentchallenging-indigenous-students-through-effortful-mathematics-teaching.

Lakehead University (2020). Indigenous Terminology. Available at: https:// teachingcommons.lakeheadu.ca/indigenous-terminology.

LaPierre, J. I. (2019). Mapping the Landscape of Indigenous Student success. (Doctoral Dissertation). Vancouver: University of British ColumbiaAvailable at: https://open.library.ubc.ca/cIRcle/collections/ubctheses/24/items/1.0384582.

Lee, T. S. (2015). The Significance of Self-Determination in Socially, Culturally, and Linguistically Responsive (SCLR) Education in Indigenous Contexts. J. Am. Indian Educ. 54 (1), 10-32.

Li, C., and Lalani, F. (2020). The COVID-19 Pandemic Has Changed Education Forever, This Is How. World Economic Forum. Available at: https://www. weforum.org/agenda/2020/04/coronavirus-education-global-covid19-onlinedigital-learning/.

Lipka, J., Sharp, N., Brenner, B., Yanez, E., and Sharp, F. (2005). The Relevance of Culturally Based Curriculum and Instruction: The Case of Nancy Sharp. J. Am. Indian Educ. 44 (3), 31-54.

Lum, Z-A. (2015). Liberals' Indigenous Affairs Name Change Called 'important Symbolic Gesture. The Huffington Post Canada. Available at: http://www. huffingtonpost.ca/2015/11/04/aboriginal-affairs-name-change_n_8475496.html doi:10.4324/9781315790947

Marule, T. O. (2012). Niitsitapi Relational and Experiential Theories in Education. Can. J. Native Educ. 35 (1), 131-143.

McMillan, A. D., and Yellowhorn, E. (2004). First Peoples in Canada. Vancouver: Douglas \&McIntyre. doi:10.5962/bhl.title.23666

Merriam, S. B., and Tisdell, E. J. (2016). Qualitative Research: A Guide to Design and Implementation. 4th ed. San Francisco, CA: Jossey-Bass.

Ministry of Education, Government of Saskatchewan (2018). Inspiring success: First Nations and Métis PreK-12 Education Policy Framework. Available at: https://pubsaskdev.blob.core.windows.net/pubsask-prod/107115/107115-Inspiring Success_Policy_Framework.pdf.

Nagy, P. (2000). The Three Roles of Assessment: Gatekeeping, Accountability, and Instructional Diagnosis. Can. J. Educ. / Revue canadienne de l'éducation 25 (4), 262-279. doi:10.2307/1585850

National Academy of Education (2021). Educational Assessments in the Covid-19 Era and beyond (Washington, DC: Author). Available at: https://naeducation. org/wp-content/uploads/2021/02/Educational-Assessments-in-the-COVID-19Era-and-Beyond.pdf.

Nelson-Barber, S., and Trumbull, E. (2007). Making Assessment Practices Valid for Indigenous American Students. J. Am. Indian Educ. 46 (3), 132-147. Available at: https://www.jstor.org/stable/24398547.

O'Leary, Z. (2017). The Essential Guide to Doing Your Research Project. 3rd ed. Los Angeles, CA: Sage.

Özerk, K., and Whitehead, D. (2012). The Impact of National Standards Assessment in New Zealand, and National Testing Protocols in Norway on
Indigenous Schooling. Int. Electron. J. Elem. Educ. 4 (3), 545-561. Available at: https://eric.ed.gov/?id=EJ1070447.

Patton, M. Q. (2015). Qualitative Research \& Evaluation Methods. 4th ed. Los Angeles, CA: Sage. doi:10.1002/9781405165518.wbeoss012.pub2

Perso, T., and Hayward, C. (2020). Teaching Indigenous Students: Cultural Awareness and Classroom Strategies for Improving Learning Outcomes. New York, NY: Rutledge.

Peters, M. A., and Mika, C. T. (2017). Aborigine, Indian, Indigenous or First Nations?. Educ. Philos. Theor. 49 (13), 1229-1234. Available at: www. tandfonline.com/doi/pdf/10.1080/00131857.2017.1279879?needAccess=true doi:10.1080/00131857.2017.1279879

Philpott, D. (2006). Identifying the Learning Needs of Innu Students: Creating a Model of Culturally Appropriate Assessment. Can. J. Native Stud. 26 (2), 361-381. Available at: http://www3.brandonu.ca/cjns/26.2/07philpott.pdf.

Piquemal, N., and Nickels, B. (2005). Cultural Congruence in the Education of and Research with Young Aboriginal Students: Ethical Implications for Classroom Researchers. Alberta J. Educ. Res. 51 (2), 118-134.

Preston, J. P., and Claypool, T. R. (2013). Motivators of Educational success: Perceptions of Grade 12 Aboriginal Students. Can. J. Educ. 36 (4), 257-279. Available at: https://journals.sfu.ca/cje/index.php/cje-rce/article/view/1233/1661.

Preston, J. P. (2019). "Indigenous and Western Worldviews: Fostering Ethical Space in the Classroom," in Knowing the Past, Facing the Future: Indigenous Education in Canada. Editor S. Carr-Stewart (Vancouver, BC: UBC Press), 140-164.

Preston, J. P. (2017). Insight from Nunavut Educators Using Appreciative Inquiry. Alberta J. Educ. 63 (3), 233-248. Available at: https://journalhosting.ucalgary. ca/index.php/ajer/article/view/56156/pdf.

Queen's University (2019). Queen's University: Indigenous Terminology Guide. Available at: https://www.queensu.ca/indigenous/sites/webpublish.queensu.ca. oiiwww/files/files/QU-Indigenous-Terminology-Guide.pdf (Accessed February 3, 2021).

Queensland Government (2015). Aboriginal and Torres Strait Islander Cultural Capability: Communicating Effectively with Aboriginal and Torres Strait Islander People. Available at: https://www.health.qld.gov.au/_data/assets/ pdf_file/0021/151923/communicating.pdf (Accessed February 4, 2021).

Rameka, L. (2012). Culturally Located Assessment in Early Childhood Education. Waikato J. Educ. 17 (2), 7-21. Available at: file:///C:/Users/janew/Downloads/ Culturally_located_assessment_in_early_childhood_e.pdf. doi:10.15663/ wje.v17i2.12

Reid, M. D., and Sam, A. H. (2021). Reflections on Assessment in the Wake of Change from the COVID-19 Pandemic. Med. Educ. 55 (1), 128-130. doi:10.1111/medu.14368

Riley, L., and Johansen, M. (2019). Creating Valuable Indigenous Learning Environments. J. Public Aff. Educ. 25 (3), 387-411. doi:10.1080/ 15236803.2018.1429815

Robinson, J. P. (2010). He Effects of Test Translation on Young English Learners' Mathematics PerformanceEduc. Res., 39, 582-590. doi:10.3102/ 0013189X103898118

Sang, K., and Worchel, J. (2017). A Place-Based Process for Reimagining Learning in the Hawaiian Context. Voice Urban Educ. 46 (1), 26-32. Available at: http:// vue.annenberginstitute.org/issues/46/place-based-process-reimagining-learninghawaiian-context.,

Smith, M., Teemant, A., and Pinnegar, S. (2004). Principles and Practices of Sociocultural Assessment: Foundations for Effective Strategies for Linguistically Diverse Classrooms. Multicultural Perspect. 6 (2), 38-46. Available at: https:// eric.ed.gov/?id=EJ940283 doi:10.1207/s15327892mcp0602_8

Solano-Flores, G., Backhoff, E., Contreras-Niño, L. A., and Vázquez-Muñoz, M. (2015). Language Shift and the Inclusion of Indigenous Populations in LargeScale Assessment Programs. Int. J. Test. 15 (2), 136-152. doi:10.1080/ 15305058.2014.947649

Solano-Flores, G., and Nelson-Barber, S. (2001). On the Cultural Validity of Science Assessments. J. Res. Sci. Teach. 38 (5), 553-573. doi:10.1002/tea.1018

Solano-Flores, G., and Trumbull, E. (2003). Examining Language in Context: The Need for New Research and Practice Paradigms in the Testing of Englishlanguage Learners. Educ. Res. 32 (2), 3-13. Available at: https://www.colorado. edu/education/sites/default/files/attached-files/Examining\%20Language\%20in \%20Context.pdf doi:10.3102/0013189x032002003

Solano-Flores, G., Trumbull, E., and Nelson-Barber, S. (2002). Concurrent Development of Dual Language Assessments: An Alternative to Translating 
Tests for Linguistic Minorities. Int. J. Test. 2 (2), 107-129. doi:10.1207/ S15327574IJT0202_2

Stoffer, J., and Australian (2017). The Importance of Culturally Safe Assessment Tools for Inuit Students. J. Indigenous Educ. 46 (1), 64-70. doi:10.1017/jie.2016.30

Stosowana, L. (2016). The Learning of and in Sami in the Norwegian School Education. Appl. Linguistics 17 (2), 81-91. Available at: http://www.ls.uw.edu. pl/en/ doi:10.32612/uw.20804814.2016.2.pp.81-91

Trumbull, E., and Nelson-Barber, S. (2019). The Ongoing Quest for CulturallyResponsive Assessment for Indigenous Students in the U.S. Front. Educ. 4 (40), 1-11. doi:10.3389/feduc.2019.00040

Trumbull, E., Sexton, U., Nelson-Barber, S., and Johnson, Z. (2015). Assessment Practices in Schools Serving American Indian or Alaska Natives Students. J. Am. Indian Educ. 54 (3), 5-30. doi:10.3389/feduc.2019.00040

Trumbull, E., and Solano-Flores, G. (2011). "The Role of Language in Assessment," in Cultural Validity in Assessment: Addressing Linguistic and Cultural Diversity. Editors M. Basterra, E. Trumbull, and G. Solano-Flores (New York, NY: Routledge), 22-45.

Vélez-Ibáñez, C., and Greenberg, J. (2005). "Formation and Transformation of Funds of Knowledge," in Funds of Knowledge: Theorizing Practices in Households, Communities, and Classrooms. Editors L. González and C. Amanti (Mahwah, NJ: Erlbaum), 47-70.

Verwoord, R., Mitchell, A., and Machado, J. (2011). Supporting Indigenous Students through a Culturally Relevant Assessment Model Based on the Medicine Wheel. Can. J. Native Educ. 34 (1), 49-66.
Vygotsky, L. (1978). Mind in Society: The Development of Higher Psychological Processes. Cambridge, MA: Harvard University Press.

Wilks, J., Dwyer, A., Wooltorton, S., and Guenther, J. (2020). We Got a Different Way of Learning:' A Message to the Sector from Aboriginal Students Living and Studying in Remote Communities. Aust. Universities' Rev. 62 (2), 25-38. Available at: https://files.eric.ed.gov/fulltext/EJ1267569.pdf.

Wiltse, K. (2011). But My Students All Speak English:" Ethical Research Issues of Aboriginal English. TESL. Can. J. 28 (5), 53-71. doi:10.18806/tesl.v28i0.1081 Wylie, E. C., Lyon, C. J., and Goe, L. (2009). Teacher Professional Development Focused Formative Assessment: Changing Teachers, Changing Schools. Princeton, NJ: Educational Testing ServiceAvailable at: https://files.eric.ed. gov/fulltext/ED505558.pdf.on

Conflict of Interest: The authors declare that the research was conducted in the absence of any commercial or financial relationships that could be construed as a potential conflict of interest.

Copyright (c) 2021 Preston and Claypool. This is an open-access article distributed under the terms of the Creative Commons Attribution License (CC BY). The use, distribution or reproduction in other forums is permitted, provided the original author(s) and the copyright owner(s) are credited and that the original publication in this journal is cited, in accordance with accepted academic practice. No use, distribution or reproduction is permitted which does not comply with these terms. 